\title{
Systems pharmacology based approach to investigate the in-vivo therapeutic efficacy of Albizia lebbeck (L.) in experimental model of Parkinson's disease
}

\author{
Uzma Saleem $^{1 *}$ D, Zohaib Raza ${ }^{1}$, Fareeha Anwar², Zunera Chaudary ${ }^{1}$ and Bashir Ahmad ${ }^{2}$
}

\begin{abstract}
Background: Parkinson's disease (PD) is a progressive neurodegenerative disorder characterized by loss of dopaminergic neurons in substantia nigra pars compacta and clinically manifested mainly with motor dysfunctions. Plants are rich source of medicinally important bioactive compounds and inhabitants of underdeveloped countries used plants for treatment of various ailments. Albizia lebbeck has been reported to possess antioxidant and neuroprotective properties that suggest the evaluation of its traditional therapeutic potential in neurodegenerative diseases.

The aim of present study was to validate the traditional use of Albizia lebbeck (L.) and delineate its mechanism of action in PD. The systems pharmacology approach was employed to explain the Albizia lebbeck (L.) mechanism of action in PD.
\end{abstract}

Methods: The haloperidol-induced catalepsy was adopted as experimental model of PD for in-vivo studies in wistar albino rats. The systems pharmacology approach was employed to explain the Albizia lebbeck (L.) mechanism of action in PD.

Results: In-vivo studies revealed that Albizia lebbeck improved the motor functions and endurance as demonstrated in behavioral studies which were further supported by the rescue of endogenous antioxidant defense and reversal of ultrastructural damages in histological studies. System pharmacology approach identified 25 drug like compounds interacting with 132 targets in a bipartite graph that revealed the synergistic mechanism of action at system level. Kaemferol, phytosterol and okanin were found to be the important compounds nodes with prominent target nodes of TDP1 and MAPT.

Conclusion: The therapeutic efficiency of Albizia lebbeck in PD was effectively delineated in our experimental and systems pharmacology approach. Moreover, this approach further facilitates the drug discovery from Albizia lebbeck for PD.

Keywords: System pharmacology, PD, Haloperidol, Albizia lebbeck

\footnotetext{
* Correspondence: Uzma95@gmail.com

${ }^{1}$ Department of Pharmacology, Faculty of Pharmaceutical Sciences,

Government College University, Faisalabad, Pakistan

Full list of author information is available at the end of the article
}

(c) The Author(s). 2019 Open Access This article is distributed under the terms of the Creative Commons Attribution 4.0 International License (http://creativecommons.org/licenses/by/4.0/) which permits unrestricted use, distribution, and reproduction in any medium, provided you give appropriate credit to the original author(s) and the source, provide a link to the Creative Commons license, and indicate if changes were made. The Creative Commons Public Domain Dedication waiver (http://creativecommons.org/publicdomain/zero/1.0/) applies to the data made available in this article, unless otherwise stated. 


\section{Background}

Parkinson's disease (PD) is a chronic age-related neurodegenerative disorder characterized mainly with motor dysfunctions including resting tremors, muscular rigidity, bradykinesia and postural reflex impairments. It has been prevalent in 10 million people around the globe with incidence rate of $219 / 100000$ people in Pakistan [1]. There has been evidence that suggests the oxidative stress, accumulation of misfolded protein and the loss the dopaminergic neurons in substantia nigra pars compacta as the main hallmarks of PD pathogenesis [2]. The neurodegeneration has been accounted for the loss of $80 \%$ dopaminergic neurotransmission in striatum that leads to significant neuromuscular dysfunction along with some cognitive deficits at advanced stages [3]. Levodopa is the primary gold standard approach to symptomatically manage the PD but its chronic use has also been associated with development of dyskinesia [4]. Moreover, we have no therapeutic options that provides the neuroprotection or relieve the progression of PD. Therefore, it is the need of time to develop the therapeutic modalities that changes the course of PD progression along with treating it symptomatically.

Plants have been increasingly reported to possess the diverse range of therapeutic compounds in the development of therapeutic options for PD [5]. However, it is costly and tedious to characterize the therapeutic roles of a plant species to the diverse or complex nature of bioactive phytochemicals present in it. Recently, the approach of systems pharmacology has been emerged as a sophisticated tool to dissect the complex pharmacological behavior of phytochemicals within the plant species. This approach integrates the high-dimensional biological data for phytochemicals to construct the computational model to explain their synergism in the development of pharmacological space at the biological systems level. The system pharmacology model extrapolates the phytochemicals from molecular or cellular to organism level in the form of biological network that better explain the mechanism of action and potential drug development from plant species [6]. Albizia lebbeck (L.) Benth, commonly known as Siris, is a large deciduous tree native to tropical southern Asia, widely cultivated in other tropical and subtropical regions. It is a tree with bi-pinnate leaves and white fragrant flowers with a fruit that is a pod containing six to twelve seeds [7]. Traditionally, pods and seeds have been widely used as antiprotozoal, anti-asthmatic, anticancer, antidiabetic, antidiarrheal, aphrodisiac and as a brain tonic [8]. The alcoholic extract of Albizia lebbeck (L.) has been reported to possess antihistaminic property, by neutralizing histamine directly or due to corticotrophic action [9]. Alcoholic extract of the stem bark of Albizia lebbeck (L.) was further corroborated to possess the strong analgesic and moderate anti-inflammatory activities possibly due to the presence of steroids and steroidal glycosides [10]. A study suggested that $70 \%$ ethanolic extract of bark of Albizia lebbeck (L.) also possess antioxidant and hepatoprotective effects owing to its principle phenolic components [11]. Moreover, the aqueous extract of Albizia lebbeck (L.) was found to reduce oxidative stress in alloxan-induced diabetic rats [12]. Albizia lebbeck (L.) bark has been found to be involved in disturbed testicular somatic cell function owing to its antifertility potential [13]. Albizia lebbeck is a diverse source of bioactive secondary metabolites including the higher content of saponins, vitamins and polyphenolics or flavonoids owing to its potential antioxidant activity or may be the therapeutic properties [14-16]. The polyphenolics have also been widely conferred with therapeutic potential to fix the redox balance and induction of endogenous antioxidant defense $[17,18]$. There are mounting evidences that addresses the role of oxidative stress to regulate the dopamine metabolism, neuro-inflammation and neuronal loss in Parkinson's [19]. Moreover, Albizia lebbeck has also been found to modulate the locomotion and motor coordination of experimental convulsive rats [20]. Despite its potent antioxidant and neuro-modulatory capacity, the neuropharmacological studies of Albizia lebbeck (L.) has been limited to anticonvulsant, antidepressant and anxiolytic activities with no direct evidence related to major neurodegenerative disorder i.e. Parkinson's [20-22]. These insights provide reasonable justifications to further evaluate the traditional use of Albizia lebbeck in neurodegenerative disorders. Therefore, this study is aimed to employ the In-vivo and system's pharmacology approach to validate the traditional use and investigate the mechanism of action of the Albizia lebbeck (L.) in Parkinson's disease.

\section{Methods \\ Experimental validation \\ Chemicals}

Methanol, Trichloroacetic acid (TCA), 5,5' -dithio-bis(2nitrobenzoic acid) (DTNB), Hydrogen Peroxide $\left(\mathrm{H}_{2} \mathrm{O}_{2}\right)$, potassium dihydrogen phosphate, pyragallol, potassium hydroxide, di-potassium hydrogen phosphate were purchased from Sigma-Aldrich (USA). Ketamine was obtained from Caraway pharmaceutical (Pakistan). Sinemet was obtained from OBS (Pakistan). All the chemicals used were of analytical grade.

\section{Collection and authentication of plant material}

The Albizia lebbeck (L.) seeds were collected from botanical garden of University of Agriculture Faisalabad (UAF), Faisalabad and authenticated by taxonomist Dr. Mansoor (UAF) with authentication voucher specimen (620-1-18) deposited in UAF Herbarium. 


\section{Preparation of plant material and aqueous methanolic Albizia lebbeck (L.) extract (ALE)}

Seeds were washed with tap water, air dried, grinded by mechanical milling and sifted into a fine powder that was subjected to cold extraction. Powder material $(1 \mathrm{~kg})$ was cold macerated in 1:2 ratio with $80 \%$ aqueous methanolic solvent $(2 \mathrm{~L})$ with $12 \mathrm{~h}$ periodic stirring for 14 days. At the end of maceration, macerate was subjected to primary filtration through filtration cloth to obtain the supernatant filtered off the macerated powder material. The supernatant was filtered through Whatman No. 1 filter paper in secondary filtration to remove the suspended solid particles from filtrate. Subsequently, the solvent in pure filtrate was evaporated by rotary evaporator under reduced pressure at $40-45^{\circ} \mathrm{C}$ that provided $9.9 \%$ extract yield percentage of pure extract.

\section{In-vivo anti-Parkinson's activity Ethical approval for animal studies}

The experimental study (No. 19589) was performed after getting ethical approval from Institutional Review Board with reference no. GCUF/ERC/1989 ruled under the regulation of Institute of Laboratory Animal Resources, Commission on Life Sciences University, National Research Council (1996).

\section{Animals and husbandry}

The experimental studies were performed on healthy wistar albino rats of same age, sex and strain. The rats were purchased from University of Agriculture Faisalabad (UAF), Faisalabad and maintained on laboratory diet with water ad libitum in animal house of Government College University Faisalabad (GCUF), Faisalabad. The rats were acclimatized for one week prior to experimental studies and kept in stainless steel cages in a temperature control $\left(24 \pm 1^{\circ} \mathrm{C}\right)$ and chemical free environment with natural light and dark cycle. Personalized human care was provided to all rats and experiments were conducted in a noiseless facility under adequate light system.

\section{Experimental design}

The following experimental model was followed to evaluate the pharmacological potential of Albizzia lebbeck (L.) in Parkinson's disease:
a) Group I: Normal control (NC);
b) Group II: Disease control (HPD);
c) Group III: Standard control (STD);
d) Group IV: $100 \mathrm{mg} / \mathrm{kg}$ treatment control (ALE 100);
e) Group V: $200 \mathrm{mg} / \mathrm{kg}$ treatment control (ALE 200);
f) Group VI: $300 \mathrm{mg} / \mathrm{kg}$ treatment control (ALE 300);

Total 36 rats were employed. There were six rats $(n=$ 6) weighing $100-150 \mathrm{~g}$ in each group.
The method of chitra et al. was used to induce the Parkinson's in experimental rats [23]. Normal control group (Group I) received the distilled water as vehicle. The intraperitoneal injection of haloperidol $(1 \mathrm{mg} / \mathrm{kg})$ was administered to group II-VI for 21 days to induce the catalepsy in rats. However, the Group III was treated with standard (Sinemet - levodopa $100 \mathrm{mg}+$ carbidopa $25 \mathrm{mg} / \mathrm{kg}$ per oral) and groups IV-VI were administered with $100,200,300 \mathrm{mg} / \mathrm{kg}$ per oral, respectively, doses of ALE 30 min before the haloperidol administration. At the end of treatment for 21 days, the behavioral testing of rats was conducted to assess the catalepsy and motor functions.

\section{Behavioral tests}

\section{Assessment of catalepsy}

Mograbi et al., (2017) method was adopted for induction of catalepsy [24]. Functional assessment of catalepsy was performed by the bar method. The wooden bar (diameter $1 \mathrm{~cm}$ ) was utilized for this purpose that was elevated $3 \mathrm{~cm}$ from floor. Both forelimbs of rats were placed on the bar and time (seconds) was recorded for the rats to correct their imposed position. End point of catalepsy was considered when rat's forelimbs touched down on the floor or if they climbed on the bar. This behavioral assessment was conducted at the 30,60 and 90 min after the treatment with second drugs (i.e. standard or ALE).

\section{Hang test}

Caudal et al., (2018) method was adopted for wire hanging test [25]. This test is used to evaluate the skeleton muscle strength, tone and endurance as a function of time. The apparatus is made up of $1.5 \mathrm{~mm}$ in diameter stainless steel wire that is $10 \mathrm{~cm}$ and $45 \mathrm{~cm}$ in length and above the flat surface of apparatus respectively The rats are allowed to hang by the wire midway between the supports through their forearms and the hanging time is recorded which is proportional to the rats global muscular strength.

\section{Narrow beam walk test}

Chonpathomikunlert et al., (2018) method was adopted for narrow beam walk test with some modifications [26]. The rats trained and trialed to walk through the wooden narrow beam $(\mathrm{L} 100 \mathrm{~cm} \times \mathrm{W} 4 \mathrm{~cm}$ ) for $120 \mathrm{~s}$ to assess the motor coordination and balance of the rats. The narrow beam was attached with two opposite platforms and time latency to reach from one platform to another was recorded as a measure to motor coordination and balance in Parkinson's.

\section{Open field test}

This study was performed to assess the locomotor and exploratory behavior of animals. The apparatus for this 
study was wooden square box (W $100 \mathrm{~cm} \times \mathrm{D} 100 \mathrm{~cm} \times$ $\mathrm{H} 45 \mathrm{~cm}$ ) covered with resin and floor divided into 25 squares. Rats were allowed to move freely into the box for two minutes and following parameters were observed and recorded [27]:

a) Number of squares (both central \& peripheral) explored (i.e. Horizontal exploration)

b) Number of rearing (i.e. Vertical exploration)

After behavioral experiments, the animals were anesthetized with intramuscular injection of ketamine hydrochloride $(24 \mathrm{mg} / \mathrm{kg})$. Following anesthetization, the animals were sacrificed by decapitation to excise the brain tissue and carcass were buried. The excised brain tissues were used for histological and biochemical assessment of oxidative stress.

\section{Biochemical estimation of oxidative stress in brain}

The brain tissue were homogenized with 1:10 ratio in phosphate buffer $(7.4 \mathrm{pH})$ and centrifuged with $600 \mathrm{rpm}$ at $4{ }^{\circ} \mathrm{C}$ for $10 \mathrm{~min}$. The resultant clear supernatant was used for estimation of following biochemical parameters of oxidative stress by the method described previously [28]:

\section{Determination of GSH content}

The supernatant $(1 \mathrm{ml})$ was precipitated with $10 \%$ of TCA $(1 \mathrm{ml})$ and its aliquot was further mixed with phosphate solution $(4 \mathrm{ml})$ and $0.5 \mathrm{ml}$ DTNB reagent. The solution was further used for spectroscopic analysis at the $412 \mathrm{~nm}$ to determine the GSH content by following formula:

$$
\mathrm{GSH}=\mathrm{Y}-0.00314 \div 0.034 \times \mathrm{DF} \div \mathrm{BT} \times \mathrm{VU}
$$

Where,

$\mathrm{DF}=$ Dilution factor (i.e. 1);

$\mathrm{VU}=$ Volume of aliquot;

$\mathrm{Y}=$ absorbance at $412 \mathrm{~nm}$;

$\mathrm{BT}=$ Tissue homogenate of brain $(1 \mathrm{ml})$.

\section{Determination of superoxide dismutase (SOD) activity}

The supernatant $(0.1 \mathrm{ml})$ was added with $0.1 \mathrm{M}$ potassium phosphate buffer $(2.8 \mathrm{ml}, 7.4 \mathrm{pH})$ and solution was further used for spectroscopic analysis at $325 \mathrm{~nm}$. The standard curve of SOD was plotted by using different concentrations $(10 \mu \mathrm{L}-100 \mu \mathrm{L})$ and following regression equation was used to estimate the SOD activity

$$
\mathrm{Y}=0.0095 \mathrm{x}+0.1939
$$

\section{Determination of catalase (CAT) activity}

The supernatant $(0.05 \mathrm{ml})$ was mixed with $30 \mathrm{mM}$ hydrogen peroxide $(1 \mathrm{ml})$ and $50 \mathrm{mM}$ phosphate buffer
$(1.95 \mathrm{ml}, \mathrm{pH} 7)$ and resultant solution was subjected to spectroscopic analysis at $240 \mathrm{~nm}$ to estimate the CAT activity by following formula [29]:

$$
\begin{aligned}
\text { CAT activity }= & \delta \mathrm{OD} \div \mathrm{E} \times \text { volume of sample }(\mathrm{ml}) \\
& \times \text { mg.of protein }
\end{aligned}
$$

Where:

$\delta \mathrm{OD}=$ Changing absorbance $/$ minute .

$\mathrm{E}=$ Extinction coefficient of hydrogen peroxide (i.e. $\left.0.071 \mathrm{mmol} \mathrm{cm}^{-1}\right)$.

Standard curve of protein was plotted by using different concentration of BSA. Following regression equation was used to calculate the protein content.

$$
\mathrm{Y}=0.00007571 \mathrm{x}+0.0000476 \text {. }
$$

\section{Histological studies}

The brain tissue was fixed in $4 \%$ formaldehyde and embedded in paraffin. Then tissue was sliced into $5 \mu \mathrm{m} \mathrm{sec}-$ tions and stained with Hematoxylin and Eosin (H\&E) to examine under light microscopy [27].

\section{Statistical analysis}

The results are presented as mean \pm SEM. Data were analyzed by applying One-way and Two-way ANOVA followed by tukey multiple comparison and Bonferroni posttests, respectively by using graphpad prism version 5. Statistically, the results with $p \leq 0.05$ were considered significant.

\section{Systems pharmacology of Albizia lebbeck (L.)}

The phytochemicals of Albizia lebbeck (L.) were retrieved from Indian Medicinal Plants, Phytochemistry and Therapeutics (IMPPAT) and Dr. Duke's phytochemical and ethnobotanical database to construct the compound database [30, 31]. These compounds were screened for drug likeness as a function of Lipinski rule of 5 in Swiss ADME tool [32]. The compounds, following the Lipinski criteria, were mapped by reverse pharmacophore modelling in Swiss Target Prediction tool that utilize the knowledge-based algorithm or homology based modelling to accurately predict their target proteins [33]. The target proteins with higher estimated probability were selected to construct the target database. These proteins were further classified by Gene Ontology in Panther classification system and possible functional interactions of these targets were analyzed in STRING 10 and KEGG pathways with false discovery rate $<0.5$ were selected $[34,35]$. These KEGG pathways were indexed with KEGG disease database to probe their disease associations. The networks of compounds - targets (C-T network) and pathway - disease (P-D network) were constructed and analyzed by Cytoscape 3.2.1 [36]. 


\section{Results}

In-vivo anti-Parkinson's activity

Behavioral tests

Assessment of catalepsy Animals treated with haloperidol (HPD) exhibit significantly severe catalepsy as compared to all other group (Fig. 1). The ALE 100 group revealed significant $(P<0.005)$ improvement in catalepsy. However, the ALE 200 and ALE 300 groups were more proficient in reversal of catalepsy as it results into reversal of catalepsy significantly higher $(P<0.001)$ which was comparable to STD group. Time of catalepsy was higher $(185.3 \pm 29.67)$ at the interval of $60 \mathrm{~min}$ that ameliorated with passage of time.

\section{Hang test}

The rats treated with HPD exhibited sharp decrease in the hang time latency (Fig. 2). The treatment groups were found to increase the hang time latency in dose dependent manner. Hang time latency was higher in ALE 300 amongst the treatment group with significantly higher variation $(\mathrm{P}<0.001)$ as compared to $\mathrm{HPD}$ group. The hang time latency of this group was also comparable to the STD group. However, the time latency of ALE 100 was moderately significant as compared to the HPD group. Taking this into consideration, dose dependent increase in hang time latency can be correlated to the global muscular strength recovery in ALE 300 rats.

\section{Narrow beam walk test}

The rats treated with HPD were found to exhibit motor incoordination and imbalance typically expressing the

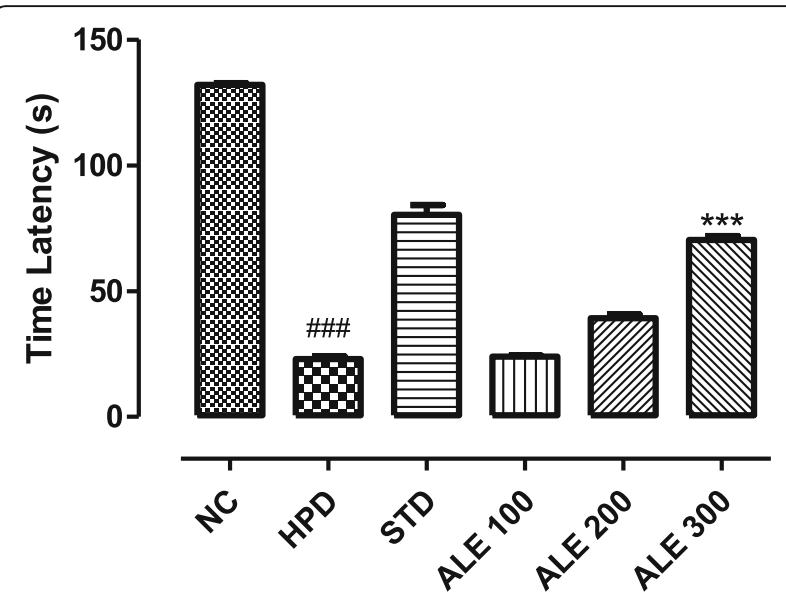

Fig. 2 Hang time latency in experimental groups; values are expressed as mean \pm SEM, $n=6$. The intergroup variation was measure by Prism one-way ANOVA followed by tukey's multiple comparison post-hoc test. ${ }^{* *} \mathrm{P} 0.001$ vs HPD group, ${ }^{\# \#} P<0.001$ vs NC (Normal control)

symptoms of Parkinson's. The time latency to reach the opposite platform was higher in the group treated with HPD alone as compared to NC group $(P<0.001)$ (Fig. 3$)$. The time latency was much lower in STD with significant variance $P<0.001$. The difference in time latency of ALE 100 and ALE 200 was non-significant $(P>0.005)$ as compared HPD group that represented the motor intoxication in these groups. The ALE 300 group, however, revealed the highly significant variance $(P<0.001)$ as compared to HPD group and nonsignificant variance $(\mathrm{P}>0.005)$ with standard group. Therefore, the rate of recovery from motor imbalance

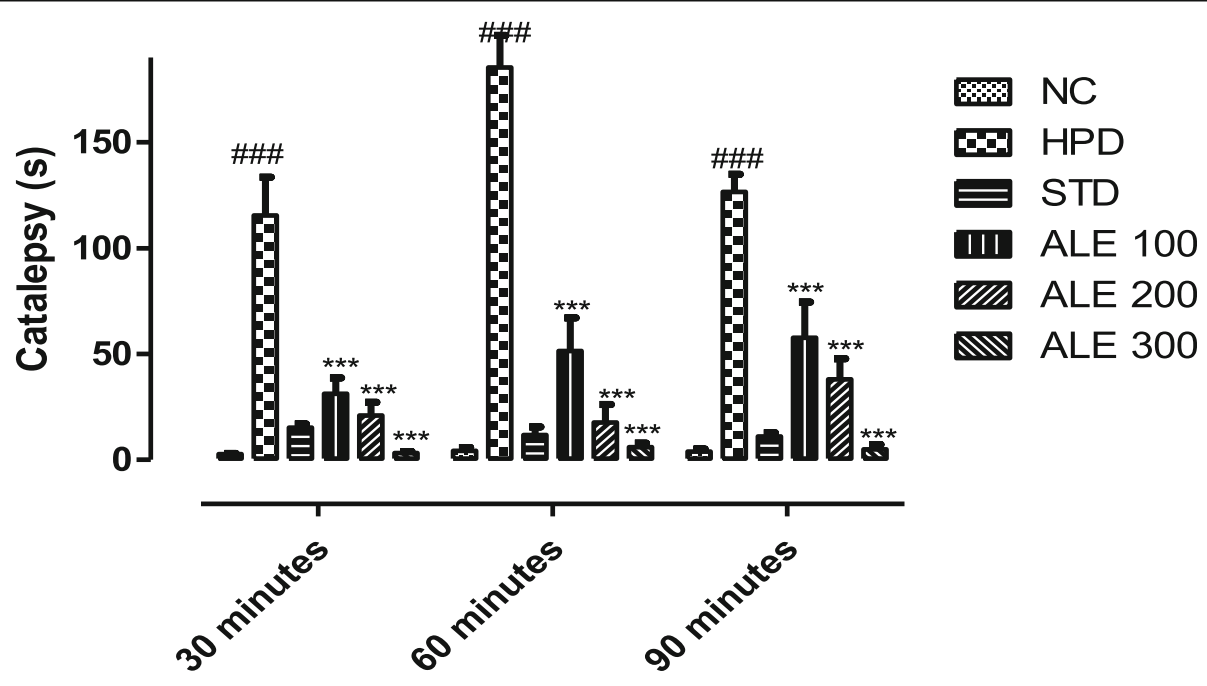

Time intervals

Fig. 1 Catalepsy in time (s) at different interval; values are expressed as mean \pm SEM, $n=6$ The intergroup and interinterval variation was measure by Prism two-way ANOVA followed by Bonferroni post-hoc test. ${ }^{* * P} 0.001$ vs HPD group, ${ }^{\# \# P}<0.001$ vs NC (Normal control). 


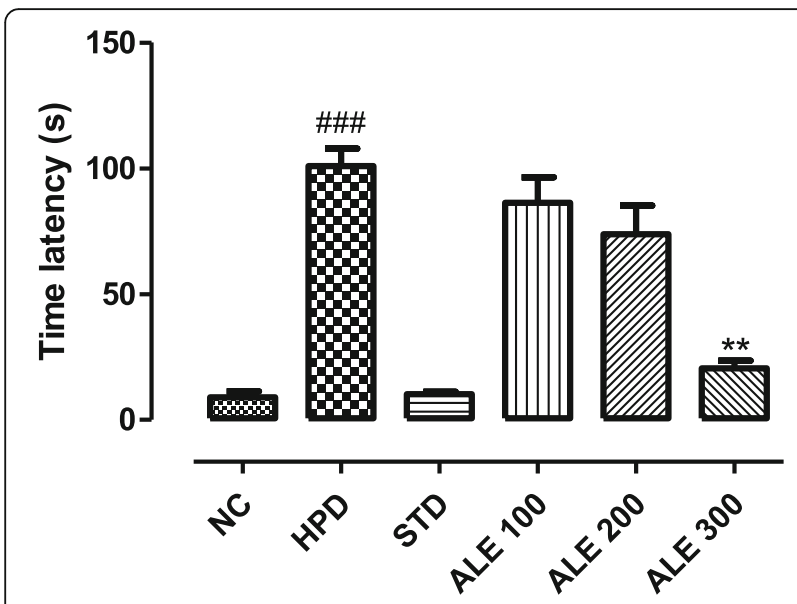

Fig. 3 Time latency to reach the opposite platform in groups; values are expressed as mean \pm SEM, $n=6$. The intergroup variation was measure by Prism one-way ANOVA followed by tukey's multiple comparison post-hoc test. ${ }^{* * P} 0.01$ vs HPD group, ${ }^{\# \#} P<0.001$ vs NC (Normal control)

or intoxication was almost equivalent to the standard group.

\section{Open field test}

The HPD treated animal exhibited the marked decrease in horizontal explorations resulting into lower locomotor activities and explorations (Fig. 4). The horizontal exploration or squares crossing were recovered in the treatment group. The highest horizontal explorations in treatment groups $(16 \pm 0.73)$ were seen in the treatment group ALE 200 with highly significant variation $(P<0.001)$. However, this standard group exhibited more reversal of horizontal explorations than all the treatment groups. The rearing shared non-significant variation $(P<0.005)$ among the group.

\section{Biochemical estimation of oxidative stress in brain}

The antioxidant enzymatic activities in rats brain tissues was assessed to measure the status of oxidative stress following induction of Parkinson's (Table 1). The content of GSH was severely depleted in HPD group as compared to NC group $(P<0.001)$. The recovery of GSH content was highly significant in treatment group ALE 300 which was comparable to replenishment of GSH in STD group $(P<0.005)$. However, the treatment groups ALE 100 and ALE 200 also showed significant recovery of GSH content as compared to HPD group $(\mathrm{P}<0.001)$. The enzymatic activity of SOD and CAT was compromised in HPD group that resulted into oxidative stress and depletion of GSH. The recovery of enzymatic activity of CAT was moderately significant in ALE 100 and ALE 200 groups $(\mathrm{P}<0.005)$. However, the recovery of CAT activity was found to be the comparable to STD group that was, in fact, highly significant rescue as compared HPD group $(\mathrm{P}<0.001)$. The variance in the SOD activity was almost same in all treatment groups and STD group as compared to the HPD group $(P>$ 0.005). The HPD group, however, had the lowest titer of SOD activity as compared to all groups.

\section{Histological studies}

Histological examination of NC section revealed the intact tissue architecture with active neuronal cells (Fig. 5). The HPD section showed the severe loss of cellular outlines and chromatic content. The severe lipids peroxidation of cell membranes was accompanying with marked neurodegeneration. The STD section was significantly replenished with healthy active neurons with normal structural outlines and chromatin content. The reversal of architectural loss was also observed in ALE 100 and ALE 200 tissue sections but with the load of partially degenerated neurons with pyknotic nuclei. The ALE 300 section significantly recovered from neuronal loss and ultrastructural damages but vacuolation still persists.

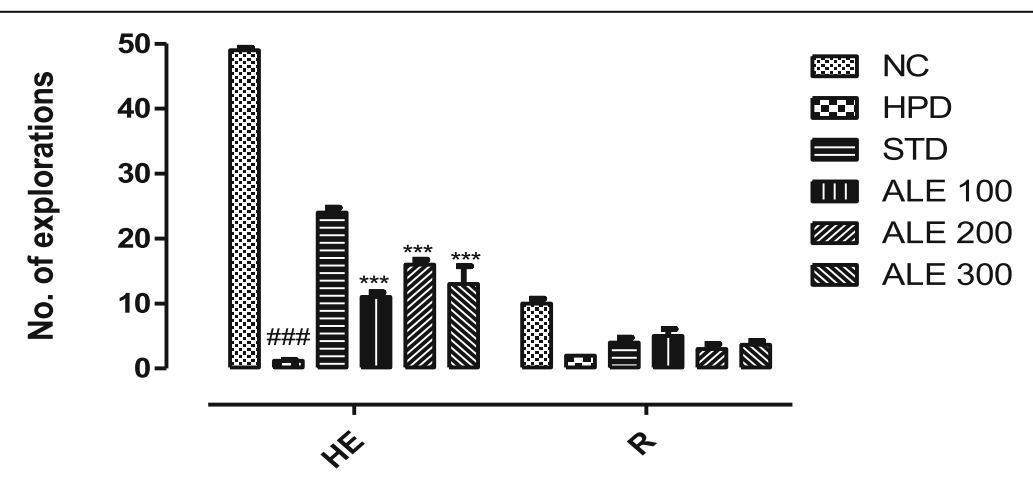

Fig. 4 Horizontal exploration and rearing among the groups; values are expressed as mean $\pm S E M, n=6$. The intergroup variation was measure by Prism two-way ANOVA followed by Bonferroni post-hoc test. HE = Horizontal exploration, R= Rearing. ***P 0.001 vs HPD group' \#\#\# $P<0.001$ vs NC (Normal control) 
Table 1 Estimation of endogenous anti-oxidant capacity in brain tissue of the experimental groups

\begin{tabular}{llllll}
\hline Groups & Treatment & DOSE & GSH $(\mu \mathrm{g} / \mathrm{mg}$ of brain tissue) & SOD $(\mu \mathrm{g} / \mathrm{mg}$ of brain tissue) & CAT $(\mu \mathrm{g} / \mathrm{mg}$ of brain tissue) \\
\hline I & Normal control & N/A & $80.67 \pm 0.866$ & $24.193 \pm 0.6776$ & $21.92 \pm 0.487$ \\
II & Disease control (HPD) & $1 \mathrm{mg} / \mathrm{kg}$ & $55.624 \pm 1.774$ & $16.4716 \pm 0.649$ & $3.0733 \pm 0.214$ \\
III & Standard control (STD) & $100 \mathrm{mg} / \mathrm{kg}$ & $79.944 \pm 1.772^{* * *}$ & $22.88 \pm 0.407^{* * *}$ & $13.0083 \pm 0.722^{* * *}$ \\
IV & Treatment control (ALE 100) & $100 \mathrm{mg} / \mathrm{kg}$ & $71.29 \pm 2.33 * * *$ & $21.513 \pm 0.574^{* *}$ & $11.612 \pm 0.485^{* * *}$ \\
V & Treatment control (ALE 200) & $200 \mathrm{mg} / \mathrm{kg}$ & $77.984 \pm 1.098^{* * *}$ & $22.234 \pm 0.627^{* *}$ & $16.1416 \pm 0.593^{* * *}$ \\
VI & Treatment control (ALE 300) & $300 \mathrm{mg} / \mathrm{kg}$ & $78.577 \pm 1.546^{* * *}$ & $23.197 \pm 0.6389^{* * *}$ & $19.55 \pm 1.209^{* * *}$ \\
\hline
\end{tabular}

*** $P<0.001$ and ${ }^{* *} P<0.01$ as compared to disease group. Each value is mean \pm SEM

\section{Systems pharmacology of Albizia lebbeck (L.)}

A total 30 representative compounds of Albizia lebbeck (L.) were retrieved from the database mining. The compounds were screened for $\log \mathrm{P}$, molecular weight, hydrogen bond donor and hydrogen bond acceptor functions as per Lipinski rule of five. All the compounds, except digitoxin, reynoutrin, vicenin 2 and rutin, passed the Lipinski criteria of drug likeness with no more than 1 violation. The list of representative compounds and their drug likeness is outlined in Table 2.

The reverse pharmacophore screening of 26 compounds, demonstrating drug likeness, yielded the 132 targets of homosapien origin except ascorbic acid. The Panther classification system classified these targets into oxidoreductase (20\%), receptors (G-Protein coupled) (17\%), hydrolases (15\%), nucleic acid binding proteins $(12 \%)$, transporter $(11 \%)$, transcription factors $(9 \%)$ and transferases (6\%) (Fig. 6). The hydrolases were distributed predominantly by proteases $(53.3 \%)$, phosphatases (33.3\%), lipases (13.3\%) and phosphodiesterases (6.7\%). The transferases, transcription factors and transporter were predominantly distributed into the subgroups of kinases (100\%), zinc finger transcription factor (77.8\%) and cation transporters (63.3\%), respectively. The panther classification analysis also revealed the involvement of these targets in variety of cellular (74\%), metabolic (70\%), biological regulation (43\%), multicellular organismal (35\%), response to stimulus (33\%), developmental (19\%), immune system (8\%) and localization (1\%) processes.

The relationship between the compounds and targets was highlighted by the bipartite graph of compound target (C-T) network of interaction (Fig. 7). The network was composed of 157 nodes (25 compounds and 132
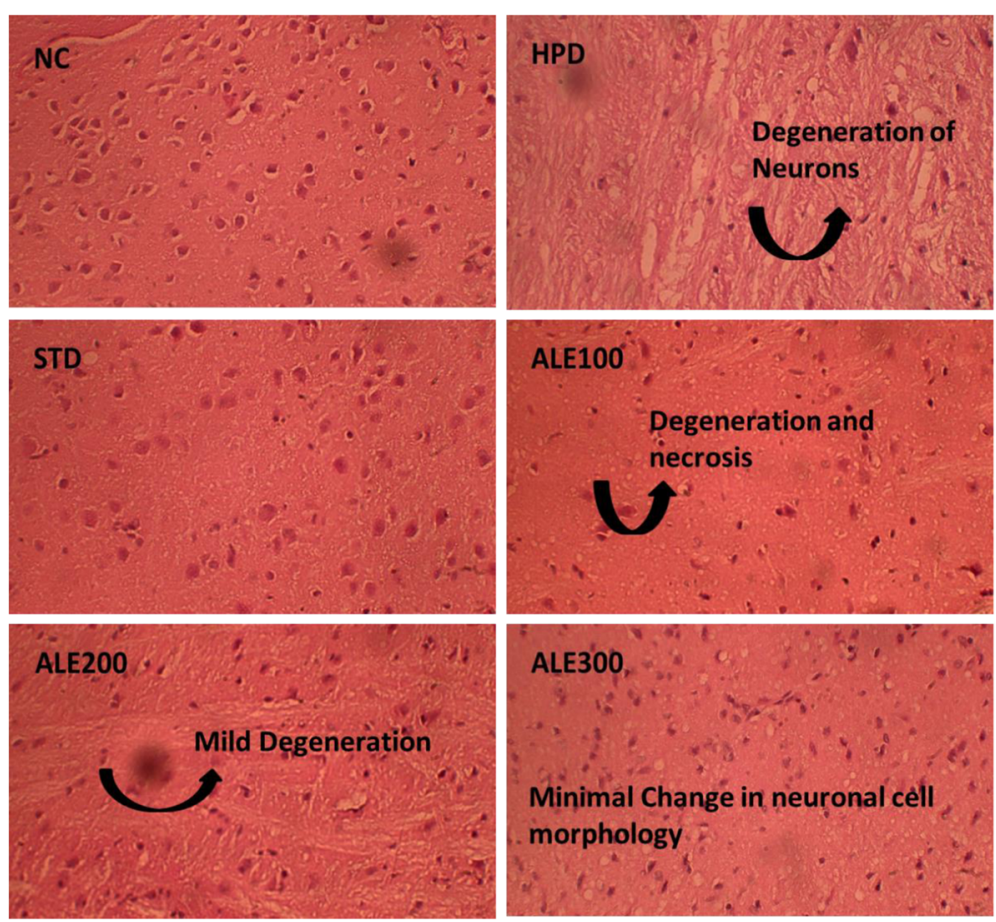

Fig. 5 Histopathological changes in the cerebral cortex of experimental group; NC: Normal control; HPD: Disease control; STD: Standard control; ALE: Albizia lebbeck (L.) extract; 100, 200 \& 300: dose levels in mg/kg 
Table 2 The representative phytochemicals of Albizia lebbeck (L.) and their corresponding druglikeness

\begin{tabular}{|c|c|c|c|c|c|c|}
\hline Compounds & Pubchem /ChEBI ID & $\log P$ & Molecular Weight & $\mathrm{H}$-donor & H-acceptor & Drug Likeness \\
\hline Albigenin & Pubchem 101,280,261 & 6.02 & 426.67 & 1 & 2 & Yes \\
\hline Albigenic acid & Pubchem 101,596,822 & 5.42 & 472.7 & 3 & 4 & Yes \\
\hline Quebrachitol & ChEBI 111 & -2.26 & 194.18 & 5 & 6 & Yes \\
\hline Phytosterol & Pubchem 12,303,662 & 7.19 & 414.17 & 1 & 1 & Yes \\
\hline Triterpenoids & Pubchem 71,597,391 & 3.94 & 472.66 & 4 & 5 & Yes \\
\hline Alpha Amyrin & Pubchem 225,688 & 7.05 & 426.72 & 1 & 1 & Yes \\
\hline Beta Amyrin & Pubchem 225,689 & 7.05 & 426.72 & 1 & 1 & Yes \\
\hline Epicatechin & Pubchem 182,232 & 0.85 & 290.27 & 5 & 6 & Yes \\
\hline Umbellic acid & Pubchem 446,611 & 0.89 & 180.16 & 3 & 4 & Yes \\
\hline Acacic acid & Pubchem 12,305,894 & 4.46 & 488.7 & 4 & 5 & Yes \\
\hline Benzoic acid & Pubchem 243 & 1.44 & 122.12 & 1 & 2 & Yes \\
\hline Benzyl alcohol & Pubchem 244 & 1.41 & 108.14 & 1 & 1 & Yes \\
\hline Celastrol & Pubchem 122,724 & 5.16 & 450.61 & 2 & 4 & Yes \\
\hline Digitoxin & Pubchem 441,207 & 2.61 & 764.94 & 5 & 13 & No \\
\hline L-arginine monocation & Pubchem 1,549,073 & -3.14 & 175.21 & 4 & 2 & Yes \\
\hline Echinocystic acid & Pubchem 73,309 & 5.3 & 472.7 & 3 & 4 & Yes \\
\hline Eupatin & Pubchem 5,317,287 & 2.12 & 360.31 & 3 & 8 & Yes \\
\hline Friedlein & Pubchem 244,297 & 7.45 & 426.72 & 0 & 1 & Yes \\
\hline Kaempferol & Pubchem 5,280,863 & 1.58 & 286.24 & 4 & 6 & Yes \\
\hline Ascorbic acid & Pubchem 54,670,067 & -1.28 & 176.12 & 4 & 6 & Yes \\
\hline Leucopelargonidin & Pubchem 3,286,789 & 0.58 & 290.27 & 5 & 6 & Yes \\
\hline Melacacidin & Pubchem 169,996 & 0.36 & 306.27 & 6 & 7 & Yes \\
\hline Melanoxetin & Pubchem 15,560,442 & 1.19 & 302.24 & 5 & 7 & Yes \\
\hline Myricitrin & Pubchem 5,281,673 & -0.23 & 464.38 & 8 & 12 & Yes \\
\hline Okanin & Pubchem 5,281,294 & 1.69 & 288.25 & 5 & 6 & Yes \\
\hline Oleanolic acid & Pubchem 10,494 & 6.06 & 456.7 & 2 & 3 & Yes \\
\hline Quercetin & Pubchem 5,280,343 & 1.23 & 302.24 & 5 & 7 & Yes \\
\hline Reynoutrin & Pubchem 5,320,863 & 0 & 434.35 & 7 & 11 & No \\
\hline Vicenin 2 & Pubchem 3,084,407 & -2.07 & 594.52 & 11 & 15 & No \\
\hline Rutin & Pubchem 24,832,108 & -1.12 & 610.52 & 10 & 16 & No \\
\hline
\end{tabular}

targets) and 321 edges between them. The global view of $\mathrm{C}-\mathrm{T}$ network represented the inner degree sorted circular layout of compounds connected to the outer circle of targets. The degree of interaction (i.e. edges) was consistent with the intensity of the color and size of the node. Higher degree of the interaction was represented by the superior node size and red color while lower degree with inferior node size and color reducing from orange to neon green. The degree sorted circular layout of compounds was consistent with anticlockwise sorting of compounds nodes with higher degree to lowest. The heterogeneity and centrality of network is 1.131 and 0.071 respectively, representing the biasness and centrality of nodes within the network. Consistently, the degree of some nodes indicated higher interactions as compared to other nodes. Most of the compounds nodes were active with higher degree of interactions. The nodes with higher degree of interaction are also called as hub that helps to understand the importance of compounds in therapeutic function of Albizia lebbeck (L.). Interestingly, the higher hit rate $>50 \%$ indicated the confidence of network to highlight the key components of Albizia lebbeck (L.). Consistently, among all the 25 compounds, 20 compounds have the degree higher than 10 with kaemferol (0.1243), phytosterol (0.1083) and okanin (0.1234) possessing highest betweenness centrality. However, topological co-efficient of melacacidin, L-arginine monocation, triterpenoids and quebrachitol was found to be zero that suggested the unique mechanism of action of these compounds as compared to synergistic behavior of other compounds. On the other hand, the tyrosyl - DNA phosphodiesterase 1 (TDP1) and microtubule-associated 


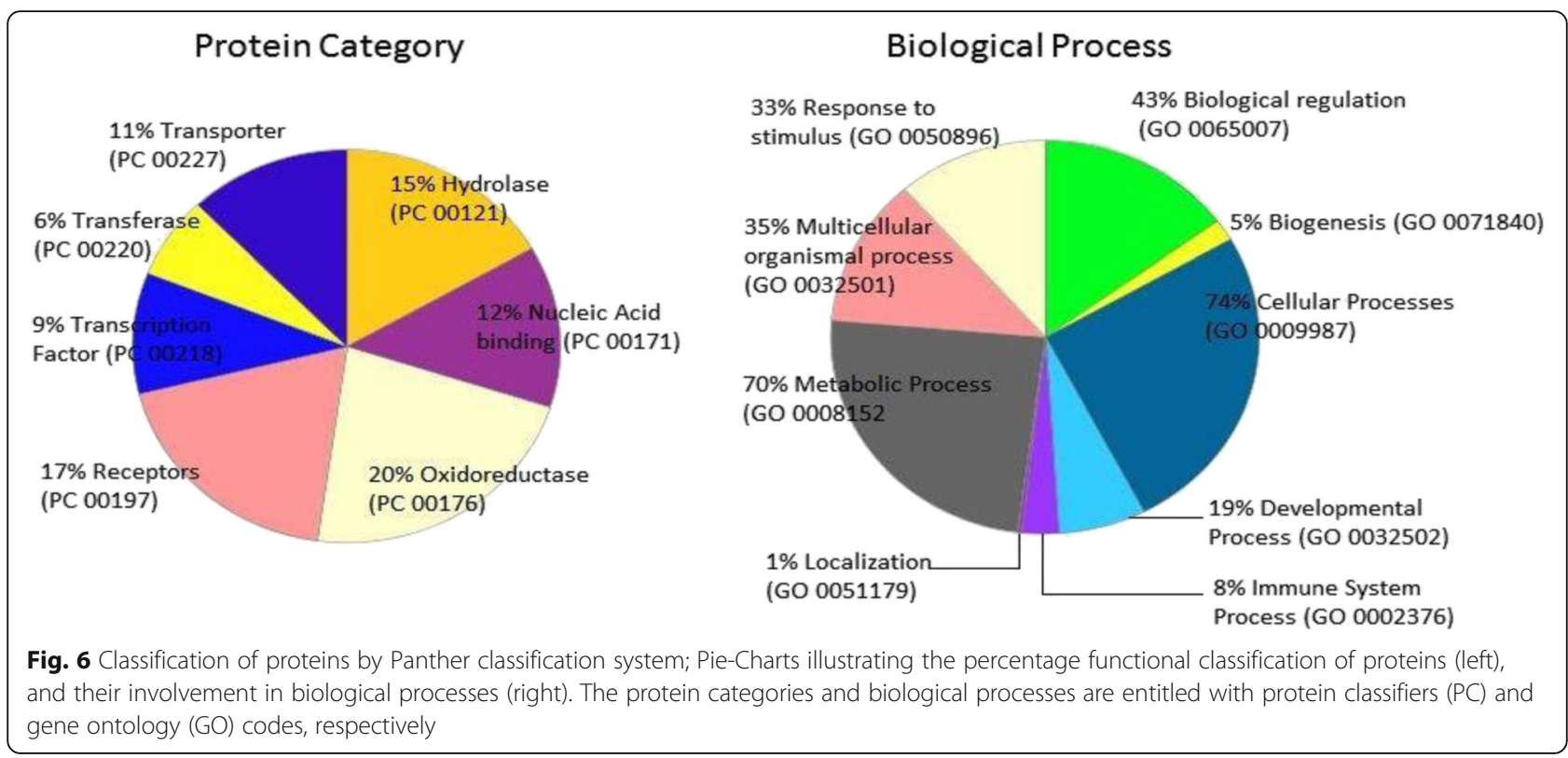

protein tau (MAPT) were found to be central targets in the interactome of Albizia lebbck (L.) compounds with 11 and 9 degree of interaction, respectively.

However, the protein-protein interaction or functional association of targets in STRING analysis enriched the 48 KEGG pathways. The detailed description of these pathways in tabulated along with their interacting proteins (Table 3). The major metabolic, PI3K-Akt signaling, Ras signaling and Rap1 signaling pathways were featured by the protein-protein interaction of $25,17,14$ and 13 proteins, respectively.

A bipartite graph was constructed to highlight the relationship of these pathways to the development of diseases at organ level (Fig. 8). This network was made of 64 nodes interacting each other with 167 edges. Peripheral nodes highlighted the disease system while central nodes represented the pathways. The size and color of nodes represented the degree of interaction as defined previously. The network centralization and heterogeneity were found to be 0.293 and 0.972 respectively, indicating the biasness and centrality among nodes. The nodes of congenital malformation, nervous system disease and metabolic disease were found to have high node degree and interacted with of 24, 21 and 21 pathways, respectively. This degree of interaction was further followed by the nodes of endocrine disease, cancer, cardiovascular and musculoskeleton disease with their interaction with 17, 14, 12 and 6 pathways, respectively.

\section{Discussion}

This study was aimed to employ the experimental and system's pharmacology approach to validate the traditional use and investigate the mechanism of action of
Albizia lebbeck (L.) in Parkinson's disease (PD). In this study, haloperidol $(1 \mathrm{mg} / \mathrm{kg})$ was intraperitoneally administered for 21 days to induce the cataleptic feature of PD. Haloperidol is a neuroleptic drug that acts primarily through dopamine receptor subtype D2 and produce the catalepsy as a extrapyramidal side effect [37]. The haloperidol induced catalepsy serve as a robust model to investigate the anti-Parkinsonian activity [38]. The catalepsy is referred to a state where animals are unable to correct their imposed postures due to motor dysfunctions [39]. The HPD group was found to be highly cataleptic as demonstrated with higher duration of catalepsy at all intervals that was consistent with literature [23]. However, the co-treatment with ALE 100, 200 and 300 significantly reduced the catalepsy in a dose dependent manner that was comparable STD. Moreover, the motor coordination and muscular strength was further assessed with the narrow beam and hang test. The HPD group revealed the lowest time latency in hang test and highest time latency to walk through the beam. However, the ALE - coadministration improved the globular muscle strength and coordination thereby reversing the motor dysfunction of Parkinson's. In addition to this, locomotor activity and exploratory activity of experimental rats was also assessed in open field test to address the cognitive and motor dysfunction associated with the Parkinson's. This test works on the principle that rats with lower cognition, skeleton muscles strength and endurance shows lower locomotor activity and exploratory behavior [27]. The HPD group revealed the marked reduction in horizontal exploration and locomotor activity as compare to STD groups. However, the ALE coadministration improved the locomotor and exploratory 


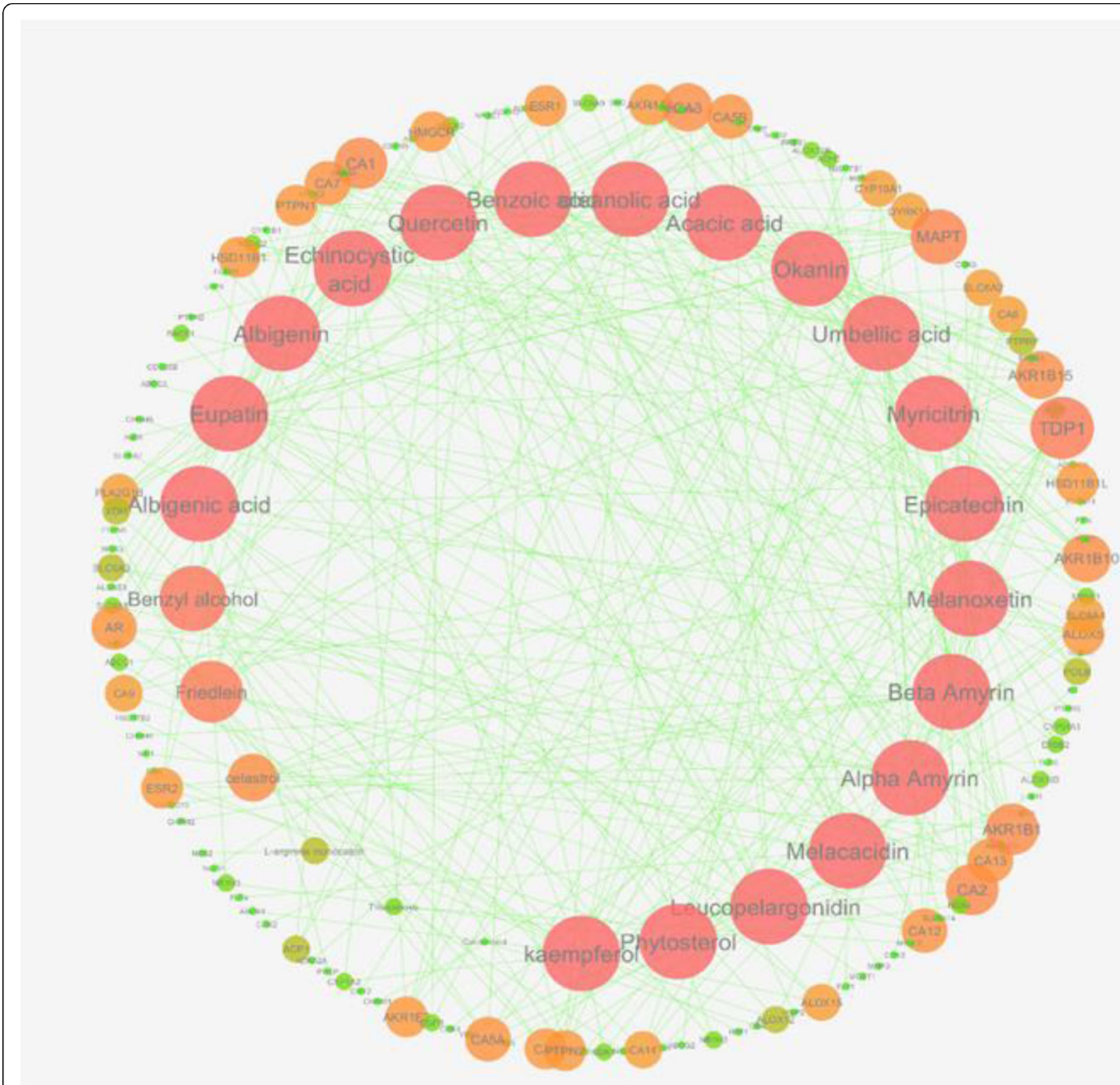

Fig. 7 Global view of compound - target (C-T) network of 25 compounds interacting with 132 targets; The compounds are representing the inner clockwise degree-sorted circle, with nodes size and colour corresponding to degree of interactions with the targets nodes in outer circle. Higher degree of connectivity is implied as big red node as compare to small green node with lower degree of connectivity

activity suggesting its role in improving the motor dysfunction of Parkinson's. Together, these behavior studies suggested the overall improvements in motor function of experimental groups treated with ALE.

In addition to its cataleptic function, the haloperidol has also been implicated as potential source of oxidative stress [40]. Interestingly, dopamine can also be metabolized to free radicals by the monoamine oxidase (MAO) or auto-oxidation in PD [41]. These reactive metabolites of dopamine can form the cysteinyl adducts at substantia nigra of PD patient thus induces the neurodegeneration [42]. Moreover, the susceptibility of $\alpha$-synuclein to reactive metabolites can also activates the microglia that further fuel the neurotoxicity [43]. In our study, the endogenous antioxidant enzymes and GSH content in the brain tissue of HPD group was severely compromised that showed acute oxidative stress consistent with previous studies [23]. Superoxidse dismutase (SOD) is a key endogenous antioxidant enzyme that has been found to be depressed in the PD and results into the neuronal load of $\mathrm{O}_{2}$ • free radicals [44]. Moreover, the activity of catalase (CAT) was also found to be compromised in PD that suggests the production of $\mathrm{OH}$ - free radicals by Fenton type reaction in neurons thus contributing to the 
Table 3 KEGG pathway enrichment and interacting proteins or targets

\begin{tabular}{|c|c|c|c|}
\hline $\begin{array}{l}\text { KEGG } \\
\text { ID }\end{array}$ & pathway description & $\begin{array}{l}\text { False } \\
\text { discovery } \\
\text { rate }\end{array}$ & Interacting proteins or targets \\
\hline 00910 & Nitrogen metabolism & $5.93 e-21$ & $\mathrm{CA1}, \mathrm{CA} 12, \mathrm{CA} 13, \mathrm{CA} 14, \mathrm{CA} 2, \mathrm{CA} 3, \mathrm{CA} 4, \mathrm{CA} 5 \mathrm{~A}, \mathrm{CA}$ B, $, \mathrm{CA} 6, \mathrm{CA} 7, \mathrm{CA} 9$ \\
\hline 04520 & Adherens junction & $3.81 \mathrm{e}-12$ & ACP1,EGFR,ERBB2,FGFR1,FYN,INSR,MET,PTPN1,PTPN6,PTPRF,SRC,YES1 \\
\hline 04151 & PI3K-Akt signalling pathway & $6.47 e-09$ & $\begin{array}{l}\text { CDK4,CDK6,CHRM1,CHRM2,CSF1R,EGFR,FGFR1,FGFR2,FGFR3,FGFR4,FLT1,FLT4,INSR,KDR,KIT, } \\
\text { MET,NOS3 }\end{array}$ \\
\hline 04014 & Ras signalling pathway & $1.22 \mathrm{e}-08$ & CSF1R,EGFR,FGFR1,FGFR2,FGFR3,FGFR4,FLT1,FLT4,INSR,KDR,KIT,MET,PLA2G1B,PTPN11 \\
\hline 04015 & Rap1 signalling pathway & $4.72 \mathrm{e}-08$ & CSF1R,EGFR,FGFR1,FGFR2,FGFR3,FGFR4,FLT1,FLT4,INSR,KDR,KIT,MET,SRC \\
\hline 04913 & Ovarian steroidogenesis & $5.27 e-08$ & ALOX5,CYP17A1,CYP19A1,CYP1B1,HSD17B1,HSD17B2,INSR,LDLR \\
\hline 04144 & Endocytosis & $1.93 e-07$ & CSF1R,EGFR,ERBB4,FGFR2,FGFR3,FGFR4,FLT1,KDR,KIT,LDLR,MET,SRC \\
\hline 00590 & Arachidonic acid metabolism & $2.04 \mathrm{e}-07$ & ALOX12,ALOX12B,ALOX15,ALOX15B,ALOX5,CYP2C19,PLA2G1B,PTGES \\
\hline 05206 & MicroRNAs in cancer & $1.05 \mathrm{e}-06$ & ABCB1,ABCC1,CDC25A,CDC25B,CDK6,CYP1B1,EGFR,ERBB2,FGFR3,MET \\
\hline 00140 & Steroid hormone biosynthesis & $1.44 \mathrm{e}-06$ & CYP17A1,CYP19A1,CYP1A2,CYP1B1,HSD11B1,HSD17B1,HSD17B2 \\
\hline 01100 & Metabolic pathways & $2.81 \mathrm{e}-06$ & $\begin{array}{l}\text { AKR1A1,AKR1B1,AKR1B10,ALOX12,ALOX12B,ALOX15,ALOX15B,ALOX5,AOX1,CYP17A1, } \\
\text { CYP19A1,CYP1A2,CYP2C19,CYP51A1,GBA,HMGCR,HSD11B1,HSD17B1,HSD17B2,NOS1,NOS2, } \\
\text { NOS3,PLA2G1B,PTGES,XDH }\end{array}$ \\
\hline 05200 & Pathways in cancer & $4.18 \mathrm{e}-06$ & AR,CDK4,CDK6,CSF1R,EGFR,ERBB2,FGFR1,FGFR2,FGFR3,KIT,MET,MMP2,NOS2 \\
\hline 05205 & Proteoglycans in cancer & $4.18 \mathrm{e}-06$ & EGFR,ERBB2,ERBB4,ESR1,FGFR1,KDR,MET,MMP2,PTPN11,PTPN6,SRC \\
\hline 04810 & Regulation of actin cytoskeleton & $2.22 \mathrm{e}-05$ & CHRM1,CHRM2,CHRM4,CHRM5,EGFR,FGFR1,FGFR2,FGFR3,FGFR4,SRC \\
\hline 04020 & Calcium signalling pathway & 4e-05 & CHRM1,CHRM2,CHRM5,EGFR,ERBB2,ERBB4,NOS1,NOS2,NOS3 \\
\hline 05219 & Bladder cancer & $7.13 e-05$ & CDK4,EGFR,ERBB2,FGFR3,MMP2 \\
\hline 04976 & Bile secretion & $8.95 e-05$ & $\mathrm{ABCB} 1, \mathrm{ABCC} 2, \mathrm{ABCG} 2, \mathrm{CA} 2, \mathrm{HMGCR}, \mathrm{LDLR}$ \\
\hline 04726 & Serotonergic synapse & 0.000115 & ALOX12,ALOX12B,ALOX15,ALOX15B,ALOX5,CYP2C19,SLC6A4 \\
\hline 00591 & Linoleic acid metabolism & 0.000464 & ALOX15,CYP1A2,CYP2C19,PLA2G1B \\
\hline 04915 & Estrogen signalling pathway & 0.000464 & EGFR,ESR1,ESR2,MMP2,NOS3,SRC \\
\hline 04510 & Focal adhesion & 0.000734 & EGFR,ERBB2,FLT1,FLT4,FYN,KDR,MET,SRC \\
\hline 04066 & HIF-1 signalling pathway & 0.000751 & EGFR,ERBB2,FLT1,INSR,NOS2,NOS3 \\
\hline 04080 & $\begin{array}{l}\text { Neuroactive ligand-receptor } \\
\text { interaction }\end{array}$ & 0.000844 & $\begin{array}{l}\text { ADRA2A,ADRA2B,ADRA2C,CHRM1,CHRM2,CHRM4,CHRM5, } \\
\text { NR3C1,PRSS1 }\end{array}$ \\
\hline 04725 & Cholinergic synapse & 0.000851 & ACHE,CHRM1,CHRM2,CHRM4,CHRM5,FYN \\
\hline 05218 & Melanoma & 0.000996 & CDK4,CDK6,EGFR,FGFR1,MET \\
\hline 05204 & Chemical carcinogenesis & 0.0011 & CYP1A2,CYP1B1,CYP2C19,HSD1 1B1,MGST1 \\
\hline 02010 & $A B C$ transporters & 0.00138 & $\mathrm{ABCB} 1, \mathrm{ABCC} 1, \mathrm{ABCC} 2, \mathrm{ABCG} 2$ \\
\hline 05215 & Prostate cancer & 0.00239 & AR,EGFR,ERBB2,FGFR1,FGFR2 \\
\hline 00232 & Caffeine metabolism & 0.00402 & CYP1A2,XDH \\
\hline 05223 & Non-small cell lung cancer & 0.00402 & CDK4,CDK6,EGFR,ERBB2 \\
\hline 05212 & Pancreatic cancer & 0.00619 & CDK4,CDK6,EGFR,ERBB2 \\
\hline 00982 & $\begin{array}{l}\text { Drug metabolism - cytochrome } \\
\text { P450 }\end{array}$ & 0.00678 & AOX1,CYP1A2,CYP2C19,MGST1 \\
\hline 05120 & $\begin{array}{l}\text { Epithelial cell signalling in } \\
\text { Helicobacter pylori infection }\end{array}$ & 0.0074 & EGFR,MET,PTPN11,SRC \\
\hline 00980 & $\begin{array}{l}\text { Metabolism of xenobiotics by } \\
\text { cytochrome P450 }\end{array}$ & 0.00805 & CYP1A2,CYP1B1,HSD11B1,MGST1 \\
\hline 04917 & Prolactin signaling pathway & 0.00873 & CYP17A1,ESR1,ESR2,SRC \\
\hline 00040 & $\begin{array}{l}\text { Pentose and glucuronate } \\
\text { interconversions }\end{array}$ & 0.01 & AKR1A1,AKR1B1,AKR1B10 \\
\hline 04010 & MAPK signalling pathway & 0.01 & CDC25B,EGFR,FGFR1,FGFR2,FGFR3,FGFR4,MAPT \\
\hline 04060 & Cytokine-cytokine receptor & 0.0119 & CSF1R,EGFR,FLT1,FLT4,KDR,KIT,MET \\
\hline
\end{tabular}


Table 3 KEGG pathway enrichment and interacting proteins or targets (Continued)

\begin{tabular}{|c|c|c|c|}
\hline $\begin{array}{l}\text { KEGG } \\
\text { ID }\end{array}$ & pathway description & $\begin{array}{l}\text { False } \\
\text { discovery } \\
\text { rate }\end{array}$ & Interacting proteins or targets \\
\hline & interaction & & \\
\hline 00380 & Tryptophan metabolism & 0.0151 & AOX1,CYP1A2,CYP1B1 \\
\hline 04012 & ErbB signalling pathway & 0.0151 & EGFR,ERBB2,ERBB4,SRC \\
\hline 04022 & cGMP-PKG signalling pathway & 0.0256 & ADRA2A,ADRA2B,ADRA2C,INSR,NOS3 \\
\hline 05202 & $\begin{array}{l}\text { Transcriptional mis-regulation in } \\
\text { cancer }\end{array}$ & 0.03 & CSF1R,FLT1,MET,MMP3,MPO \\
\hline 00561 & Glycolipid metabolism & 0.0349 & AKR1A1,AKR1B1,AKR1B10 \\
\hline 00330 & Arginine and proline metabolism & 0.0397 & NOS1,NOS2,NOS3 \\
\hline 04370 & VEGF signalling pathway & 0.0418 & $\mathrm{KDR}, \mathrm{NOS} 3, \mathrm{SRC}$ \\
\hline 04964 & $\begin{array}{l}\text { Proximal tubule bicarbonate } \\
\text { reclamation }\end{array}$ & 0.0418 & CA2,CA4 \\
\hline 05214 & Glioma & 0.0449 & CDK4,CDK6,EGFR \\
\hline 04110 & Cell cycle & 0.0483 & CDC25A,CDC25B,CDK4,CDK6 \\
\hline
\end{tabular}

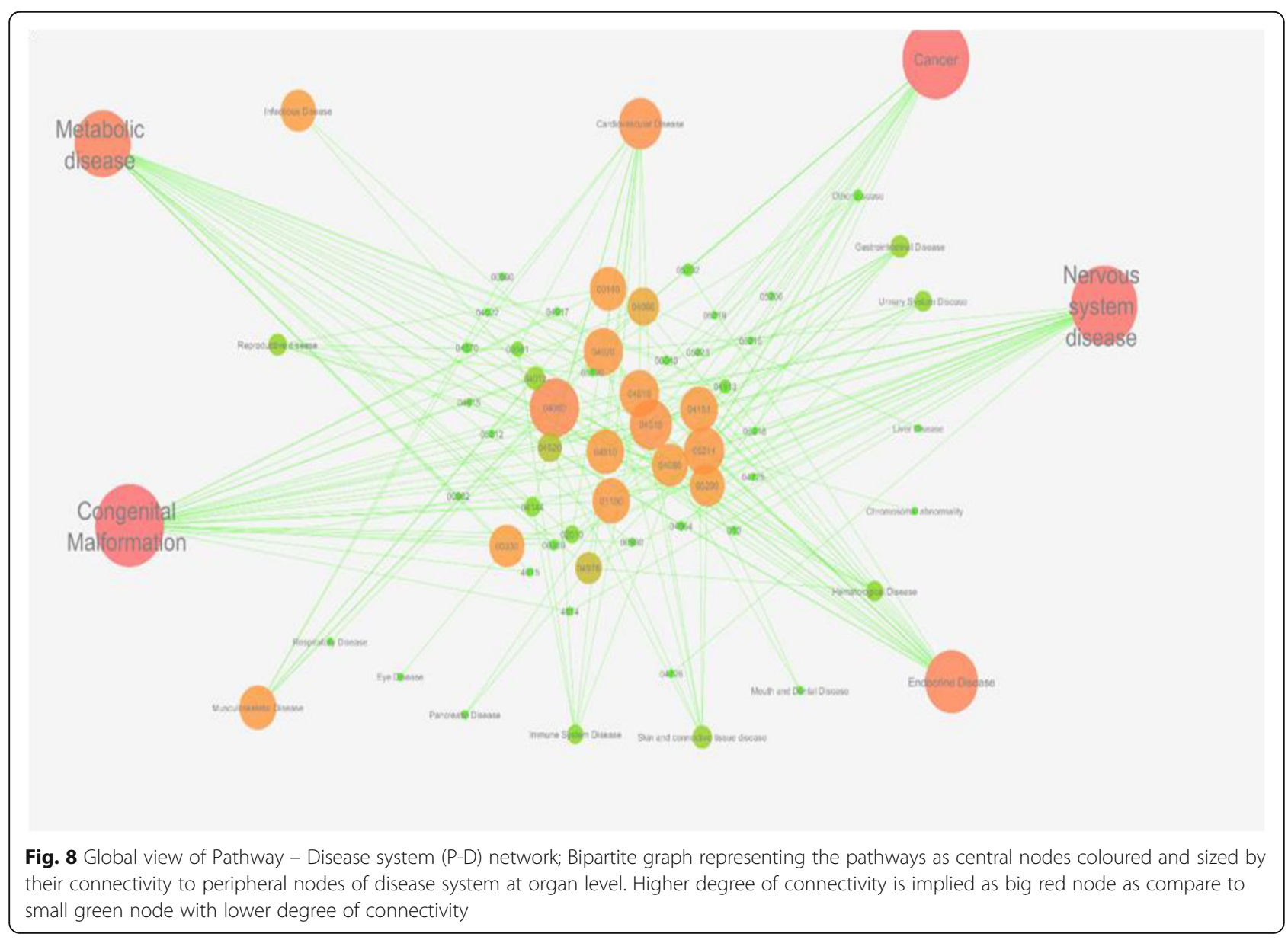


neurodegeneration in PD. Additionally, the content of GSH is depleted along the saturation of antioxidant enzyme [45]. However, the ALE co-administration significantly recovered the GSH content and activity of these enzymes thereby supported the therapeutic potential of ALE to mitigate the oxidative stress in PD. These results were further corroborated with histological studies that revealed the ALE potential to ameliorate the lipid peroxidation and neurodegeneration while reversing the tissue architecture of PD. Therefore, together these biochemical studies supported the functional outcomes of behavioral studies and advocated the therapeutic potential of ALE in the treatment of PD.

Plants are the rich source of diverse bioactive chemical species that determines the medicinal properties of them. The multi-component system and synergism between them makes the plants challenging source to probe the potential bioactive compounds responsible for their pharmacological activities. Interestingly, the virtue of synergism is complementing the emerging approach of "multi-drugs and multi-targets" with the fall of "onedrug and one target" approach due to dynamic biological systems [46]. In this context, an integrate approach of system's pharmacology has been emerged that considers the synergism of phytochemicals to approximate their pharmacological properties with potential targets in a dynamic biological system [47]. The holistic approach of systems pharmacology to integrate the genomics, proteomics, metabolomics and bioinformatics provides the exceptional platform to study the essence of synergism among the phytochemicals to treat complex diseases. Therefore, we adopted this approach to delineate the Albizia lebbeck (L.) mechanism of action in PD. In the present study, the $86 \%$ of total 30 compounds were filtered by the Lipinski rule of five for druglikeness in SwissADME. Lipinski rule of five describe the relationship between physicochemical properties and pharmacokinetics by defining the physicochemical benchmarks to predict the orally active compounds [32]. These compounds were further mapped to predict the 132 targets by reverse pharmacophore modelling in Swiss Target Prediction tool. The reverse pharmacophore approach computes the 2D and 3D pharmacophore of targets with known ligands and predict them by the measure of structural similarity [33]. The class of these targets or proteins was distinguished and relevance to biological functions was determined by PANTHER classification system. These targets were predominantly classified as oxidoreductase, receptors (G-Protein coupled), hydrolases, and nucleic acid binding proteins, transporter, transcription factors and transferases. The relevance in variety of cellular, metabolic, biological regulation, multicellular organismal, response to stimulus, developmental, immune system and localization processes suggested the vitality of these proteins in biological system. The compound-target $(\mathrm{C}-\mathrm{T})$ network explained that most of the compounds actively involved in the synergistic pattern of interaction with targets. This network also indicated that many of the compounds were interacting with more than one target and vice versa. Therefore, synergistic modulation of series of the targets by number of compounds suggested the "multi-drugs and multi-targets" as a essence to the mechanism of action of Albizia lebbeck (L.). It is generally accepted that compounds or targets with the higher degree of interaction are more pharmacologically crucial [48]. Degree is a basic topological parameter in network analysis that determine the importance of compounds and targets [49]. Betweenness centrality is another important topological parameter that determine the significance of node location within the network [50]. In our network, we found the correlation between the degree and betweenness centrality as compounds, such as kaemferol, phyosterol and okanin, demonstrated both the higher degree of interaction and betweenness centrality thus represented as key players of Albizia lebbeck (L.). The tyrosyl - DNA phosphodiesterase 1 (TDP1) and microtubule-associated protein tau (MAPT) were the central nodes amongst the targets with highest degree of interaction thus represented as the targets modulated by majority of Albizia lebbeck (L.). TDP1 is an DNA repair enzyme that has been found to catalyze breakage of the covalently linked oxidative stress induced DNA adducts at $3{ }^{\prime}$ - phosphate end and implicated as a target of various anticancer drugs [51]. It has been found to repair the oxidative stress induced single strand breaks (SSB) in astrocytes and loss of TDP1 function has also been implicated in development of progressive age-related cerebellar atrophy that highlighted its involvement in neural homeostasis [52]. MAPT encodes the tau protein that has been implicated to regulate the axonal and micro tubular function. Moreover, single nucleotide polymorphism (SNP) at MAPT has been associated with tauopathies in development of neurodegenerative disease like Alzheimer's and Parkinsonism [53]. There are also evidences that suggest the risk associated with MAPT haplotypes in the pathogenesis of PD $[54,55]$. The higher centrality or degree of interaction of these target nodes in C-T network of Albizia lebbeck (L.) represent them the key player of its mechanism of action in PD. Furthermore, the functional association of the targets in STRING analysis enriched the 48 KEGG pathways. The neuroactive ligand receptor pathway was found to be in top ten overrepresented pathway in the genome-wide association studies (GWAS) of PD [56]. The experimental evidence had suggested the association of neuroactive ligand receptor pathway in $\alpha$-synuclein toxicity in the pathogenesis of PD [57]. The serotoninergic synapses has been 
implicated as increase post-synaptic density of serotonin receptors $\left(5 \mathrm{HT}_{1 \mathrm{~A}}, 5 \mathrm{HT}_{2 \mathrm{~A}}\right)$ in neocortex of $\mathrm{PD}$ patients [58]. A study has suggested the degeneration of serotonergic terminals is an early process in the pathogenesis of PD and with preferential lower rate of degeneration as compare of dopaminergic neurons [59]. The aberrant spread of serotonergic terminals in putamen, nonphysiologically converts the exogenous levodopa and results into higher swings of dopamine that develops the levodopa associated dyskinesia [60]. The cholinergic and dopaminergic neurons are highly conserved in the striatum and extensively interact bidirectionally to regulate the motor coordination, cognitive function and rewards [61]. Cholinergic synapse has been found to induce glutamatergic and GABAergic plasticity and increase the Ach at striatum that induce the levodopa associated dyskinesia in PD [62]. Various lines of evidences have also suggested the MAPK signaling in regulation of autophagy and neurodegeneration in PD [63]. Therefore, these pathways further highlighted the functional association of interactome of Albizia lebbeck (L.) targets to the PD. However, all of the KEGG pathways were further indexed to KEGG disease database and Pathway - Disease (P-D) network was constructed to explore the therapeutic space of Albizia lebbeck (L.). The global view of network revealed that these pathways mainly interacted with the metabolic, endocrine, cancer, cardiovascular, nervous system diseased nodes which was consistent with the majority of Albizia lebbeck (L.) traditional uses [8]. Among all the disease nodes, we found that nervous system diseases node shared the highest degree of interaction with 21 pathways after the node of congenital malformation which interacted with 24 pathways. Therefore, these insights of Albizia lebbeck (L.) systems pharmacology were found to be consistent with in-vivo experimental results of anti-Parkinsonian activity and provided the deep understanding regarding its mechanism of action in PD.

\section{Conclusion}

The in-vivo experiment for anti-Parkinson's activity of Albizia lebbeck (L.) concluded that Albizia lebbeck (L.) improved the motor functions and reversed the biochemical damages in brain tissue of PD. The systems pharmacology approach in this study investigated the mechanism of action of the Albizia lebbeck (L.) in PD and clearly suggested the synergistic effect of its phytochemicals in the development of its therapeutic effect. This approach supported the theory of "multi-drug and multi target" and indicated the therapeutic efficiency of Albizia lebbeck (L.) for nervous system diseases. However, the networks also highlighted the therapeutic efficiency for other disease system that should also be deciphered experimentally.
Therefore, the present work served as the alternative strategy to provide the deep understanding of therapeutic behavior and sophistically validates the traditional uses of Albizia lebbeck (L.) to improve the efficiency of drug discovery.

\section{Abbreviations}

5HT1: Serotonin 1A receptor; 5HT2A: Serotonin 2A receptor; $A B C B 1$ : Multidrug resistance protein 1; $A B C C 1$ : Multidrug resistanceassociated protein 1; ABCC2: Canalicular multispecific organic anion transporter 1; ABCG2: ATP-binding cassette sub-family G member 2; ACHE: Acetylcholinesterase; ACP1: Low molecular weight phosphotyrosine protein phosphatase; ADRA2A: Alpha-2A adrenergic receptor; ADRA2B: Alpha-2B adrenergic receptor; ADRA2C: Alpha-2C adrenergic receptor; AKR1A1: Alcohol dehydrogenase [NADP(+)]; AKR1B1: Aldo-keto reductase family 1 member B1; AKR1B10: Aldo-keto reductase family 1 member B10; Akt: Protein kinase B; ALE 100: 100 mg/kg treatment control; ALE 200: $200 \mathrm{mg} / \mathrm{kg}$ treatment control; ALE 300: $300 \mathrm{mg} / \mathrm{kg}$ treatment control; ALE: Albizia lebbeck (L.) extract; ALOX12: Arachidonate 12lipoxygenase, 12S-type; ALOX12B: Arachidonate 12-lipoxygenase, 12R-type; ALOX15: Arachidonate 15-lipoxygenase; ALOX15B: Arachidonate 15lipoxygenase B; ALOX5: Arachidonate 5-lipoxygenase; AOX1: Aldehyde oxidase; AR: Androgen receptor; BT: Tissue homogenate of brain; CA1: Carbonic anhydrase 1; CA12: Carbonic anhydrase 12; CA13: Carbonic anhydrase 13; CA14: Carbonic anhydrase 14; CA2: Carbonic anhydrase 2; CA3: Carbonic anhydrase 3; CA4: Carbonic anhydrase 4; CA5A: Carbonic anhydrase 5A; CA5B: Carbonic anhydrase 5B; CA6: Carbonic anhydrase 6; CA7: Carbonic anhydrase 7; CA9: Carbonic anhydrase 9; CAT: Catalase; CDC25A: M-phase inducer phosphatase 1; CDC25B: M-phase inducer phosphatase 2; CDK4: Cyclin-dependent kinase 4; CDK6: Cyclin-dependent kinase 6; CGMP: Cyclic guanosine monophosphate; CHRM1: Muscarinic acetylcholine receptor M1; CHRM2: Muscarinic acetylcholine receptor M2; CHRM4: Muscarinic acetylcholine receptor M4; CHRM5: Muscarinic acetylcholine receptor M5; CSF1R: Macrophage colony-stimulating factor 1 receptor; C-T network: Compound - Target network; CYP17A1: Steroid 17alpha-hydroxylase/17,20 lyase; CYP19A1: Cytochrome P450 19A1;

CYP1A2: Cytochrome P450 1A2; CYP1B1: Cytochrome P450 1B1; CYP2C19: Cytochrome P450 2C19; CYP51A1: Lanosterol 14-alpha demethylase; DF: Dilution factor; DNA: Deoxyribonucleic acid; DTNB: 5,5'-Dithiobis-(2nitrobenzoic acid); EGFR: Epidermal growth factor receptor; ERBB2: Receptor tyrosine-protein kinase erbB-2; ERBB4: ERBB4 intracellular domain:

ESR1: Estrogen receptor; ESR2: Estrogen receptor beta; FGFR1: Fibroblast growth factor receptor 1; FGFR2: Fibroblast growth factor receptor 2; FGFR3: Fibroblast growth factor receptor 3; FGFR4: Fibroblast growth factor receptor 4; FLT1: Vascular endothelial growth factor receptor 1; FLT4: Vascular endothelial growth factor receptor 3; FYN: Tyrosine-protein kinase Fyn; GBA: Glucosylceramidase; GSH: Glutathione; GWAS: Genome-wide association studies; H\&E: Hematoxylin and Eosin; H2O2: Hydrogen Peroxide; HIF1: Hypoxia-inducible factor 1; HMGCR: 3-hydroxy-3-methylglutaryl-coenzyme A reductase; HPD: Disease control; HSD11B1: Corticosteroid 11-betadehydrogenase isozyme 1; HSD17B1: Estradiol 17-beta-dehydrogenase 1; HSD17B2: Estradiol 17-beta-dehydrogenase 2; IMPPAT: Indian Medicinal Plants, Phytochemistry and Therapeutics; INSR: Insulin receptor; KDR: Vascular endothelial growth factor receptor 2; KIT: Mast/stem cell growth factor receptor Kit; LDLR: Low-density lipoprotein receptor; MAO: Monoamine oxidase; MAPK: Mitogen-activated protein kinase; MAPT: Microtubuleassociated protein tau; MET: Hepatocyte growth factor receptor; MGST1: Microsomal glutathione S-transferase 1; MMP2: Matrix metalloproteinase-2; MMP3: Stromelysin-1; MPO: Myeloperoxidase; NC: Normal control; NOS1: Nitric oxide synthase 1; NOS2: Nitric oxide synthase 2; NOS3: Nitric oxide synthase 3; NR3C1: Glucocorticoid receptor; PD: Network Pathway - Disease network; PD: Parkinson's disease;

PI3K: Phosphoinositide 3-Kinase; PKG: Protein kinase G;

PLA2G1B: Phospholipase A2; PRSS1: Alpha-trypsin chain 1;

PTGES: Prostaglandin E synthase; PTPN1: Tyrosine-protein phosphatase nonreceptor type 1; PTPN6: Tyrosine-protein phosphatase non-receptor type 6; PTPRF: Receptor-type tyrosine-protein phosphatase F; Rap1: Ras-related protein 1; SEM: Standard error of the mean; SLC6A4: Sodium-dependent serotonin transporter; SNP: Single neucleotide polymorphism;

SOD: Superoxide dismutase; SRC: Proto-oncogene tyrosine-protein kinase Src; 
SSB: Single strand break; STD: Standard control; TCA: Trichloroacetic acid; TDP1: Tyrosyl DNA phosphodiesterase 1; VEGF: Vascular endothelial growth factor; VU: Volume of aliquot; XDH: Xanthine dehydrogenase/oxidase; YES1: Tyrosine-protein kinase Yes; $\delta O D$ : Changing absorbance / minute

\section{Acknowledgements}

Authors acknowledge the GC University and Riphah University for providing the research assistance.

\section{Authors' contributions}

U.S. designed the work and contributed in drafting; Z.R. performed experimental work; F.A. did data analysis; Z.C. did data interpretation and B.A. drafted the work and substantially revised it. All authors have read and approved the manuscript.

\section{Funding}

No funding is available for this study.

\section{Availability of data and materials}

The datasets used and/or analysed during the current study available from the corresponding author on reasonable request.

\section{Ethics approval}

The experimental study (No. 19589) was approved by Institutional Review Board (IRB) bearing reference no. GCUF/ERC/1989 which is ruled under the regulation of Institute of Laboratory Animal Resources, Commission on Life Sciences University, National Research Council (1996).

\section{Consent for publication}

All authors are agreed to have publication in BMC.

\section{Competing interests}

All authors had no conflict of interest.

\section{Author details}

${ }^{1}$ Department of Pharmacology, Faculty of Pharmaceutical Sciences, Government College University, Faisalabad, Pakistan. ${ }^{2}$ Riphah Institute of Pharmaceutical sciences, Riphah International University, Lahore, Pakistan.

Received: 16 February 2019 Accepted: 26 November 2019 Published online: 05 December 2019

\section{References}

1. Hussain G, Rasul A, Anwar H, Sohail MU, Kashif Shahid Kamran S, Baig S, Shabbir A, lqbal J. Epidemiological data of neurological disorders in Pakistan and neighboring countries: a review. Pakistan. J Neurol Sci. 2017;12(4):12.

2. Kaur R, Mehan S, Singh S. Understanding multifactorial architecture of Parkinson's disease: pathophysiology to management. Neurol Sci. 2019; 40(1):13-23.

3. Cheng $\mathrm{H}-\mathrm{C}$, Ulane $\mathrm{CM}$, Burke RE. Clinical progression in Parkinson disease and the neurobiology of axons. Ann Neurol. 2010;67(6):715-25.

4. Thanvi B, Lo N, Robinson T. Levodopa-induced dyskinesia in Parkinson's disease: clinical features, pathogenesis, prevention and treatment. Postgrad Med J. 2007;83(980):384-8.

5. Fu W, Zhuang W, Zhou S, Wang X. Plant-derived neuroprotective agents in Parkinson's disease. Am J Transl Res. 2015;7(7):1189-202.

6. Li Y, Zhang J, Zhang L, Chen X, Pan Y, Chen SS, Zhang S, Wang Z, Xiao W, Yang $L$, et al. Systems pharmacology to decipher the combinational antimigraine effects of Tianshu formula. J Ethnopharmacol. 2015;174:45-56.

7. Srivastav Neeti SS, Vijay J, Tiwari Brijesh K. Anti convulsant activity of leaf extracts of Albizia lebbeck linnn in $n$ experimental rats. Int J Pharm Sci Rev Res. 2016:173-6.

8. Verma DS, Vashishth E, Singh R, Kumari A, Meena A, Pant P, Bhuyan GC, Padhi MM. A review on parts of Albizia lebbeck (L.) Benth. Used as Ayurvedic drugs. Res J Pharm Technol. 2013;6(11):1307-13.

9. Narasimhan PB, Pandikumar P, Ignacimuthu S. Anti-inflammatory activity of Albizia lebbeck Benth., an ethnomedicinal plant, in acute and chronic animal models of inflammation. J Ethnopharmacol. 2009;125(2):356-60.

10. Abd El-Ghany AES, Dora G, Abdallah RH, Hassan W, El-Salam EA. Phytochemical and biological study of Albizia lebbeck stem bark. J Chem Pharma Res. 2015;7(5):29-43.
11. Patel T, Shirode D, Pal Roy S, Kumar S, Siddamsetty RS. Evaluation of Antioxidant and Hepatoprotective effects of 70\% ethanolic bark extract of Albizzia lebbeck in rats. Int J Res Pharm Sci. 2010;1(3):270-6.

12. Resmi $C R$, Venukumar MR, Latha MS. Antioxidant activity of Albizzia lebbeck (Linn.) Benth. In alloxan diabetic rats. Indian J Physiol Pharmacol. 2006;50(3): 297-302.

13. Gupta RS, Chaudhary R, Yadav RK, Verma SK, Dobhal MP. Effect of Saponins of Albizia lebbeck (L.) Benth bark on the reproductive system of male albino rats. J Ethnopharmacol. 2005;96(1-2):31-6.

14. El-Hawary S, Sokkar NM, El-Fouly K, Talaat Z. A phytochemical profile of Albizia lebbeck (L.) benth. Cultivated in Egypt. Asian J Biochem. 2011;6(2):122-41.

15. Zia-Ul-Haq M, Ahmad S, Qayum M, Ercisli S. Compositional studies and antioxidant potential of Albizia lebbeck L. Benth. Pods and seeds. Turk J Biol. 2013;37(1):25-32.

16. Wati $\mathrm{M}$, Khabiruddin M. Comparision of antioxidants in phenol extract and methanol extract of Albizia lebbeck from two locations. Int J Pharm Sci Rev Res Int. 2017;45(1):78-82.

17. Kasote DM, Katyare SS, Hegde MV, Bae H. Significance of antioxidant potential of plants and its relevance to therapeutic applications. Int J Biol Sci. 2015;11(8):982-91.

18. Pandey KB, Rizvi SI. Plant polyphenols as dietary antioxidants in human health and disease. Oxidative medicine and cellular longevity. 2009;2(5): 270-8.

19. Blesa J, Trigo-Damas I, Quiroga-Varela A, Jackson-Lewis VR. Oxidative stress and Parkinson's disease. Front Neuroanat. 2015;9:91.

20. Velraj M, A V, Jayakumari S, Ramamoorthy S, Jeyabalan S. Antidepressant activity of the ethanolic extract of Albizzia lebbeck (Linn) bark in animal models of depression. 2009;1:112-5.

21. Kasture VS, Chopde CT, Deshmukh VK. Anticonvulsive activity of Albizzia lebbeck, Hibiscus rosa sinesis and Butea monosperma in experimental animals. J Ethnopharmacol. 2000;71(1-2):65-75.

22. Une HD, Sarveiya VP, Pal SC, Kasture VS, Kasture SB. Nootropic and anxiolytic activity of saponins of Albizzia lebbeck leaves. Pharmacol Biochem Behav. 2001;69(3-4):439-44

23. Chitra V, KM, AM, Thamaraikani T,K G. Effect of hydroalcoholic extract of Achyranthes aspera on haloperidol-induced Parkinson's disease in Wistar rats. 2017;10(9):318-21.

24. Mograbi KM, de Castro AC, de Oliveira JA, Sales PJ, Covolan L, Del Bel EA, de Souza AS. Effects of GABAa receptor antagonists on motor behavior in pharmacological Parkinson's disease model in mice. Physiol Rep. 2017;5(6).

25. Caudal D, Guinobert I, Lafoux A, Bardot V, Cotte C, Ripoche I, Chalard P, Huchet $C$. Skeletal muscle relaxant effect of a standardized extract of Valeriana officinalis L. after acute administration in mice. JTCME J Tradit Complement Med. 2018;8(2):335-40.

26. Chonpathompikunlert $P$, Boonruamkaew $P$, Sukketsiri $W$, Hutamekalin $P$, Sroyraya M. The antioxidant and neurochemical activity of Apium graveolens L. and its ameliorative effect on MPTP-induced Parkinson-like symptoms in mice. BMC Complement Altern Med. 2018;18(1):1-12.

27. Justin Thenmozhi A, Raja TR, Janakiraman U, Manivasagam T. Neuroprotective effect of hesperidin on aluminium chloride induced Alzheimer's disease in Wistar rats. Neurochem Res. 2015;40(4):767-76.

28. Hira S, Saleem U, Anwar F, Ahmad B. Antioxidants attenuate isolation-and LDOPA-induced aggression in mice. Front Pharmacol. 2018:8:945.

29. Saleem U, Ahmad B, Ahmad M, Hussain K, Bukhari NI. Investigation of in vivo antioxidant activity of Euphorbia helioscopia latex and leaves methanol extract: a target against oxidative stress induced toxicity. Asian Pac J Trop Med. 2014;7:S369-S375.

30. Duke J, Bogenschutz MJ. Dr. Duke's phytochemical and ethnobotanical databases. USDA, Agricultural Research Service; 1994.

31. Karthikeyan Mohanraj BSK, R.P. Vivek-Ananth, R.P. Bharath Chand, S.R. Aparna, P. Mangalapandi, Areejit Samal: IMPPAT: a curated database of Indian medicinal plants, Phytochemistry Ther 2018, 8:4329.

32. Daina A, Michielin O, Zoete V. SwissADME: a free web tool to evaluate pharmacokinetics, drug-likeness and medicinal chemistry friendliness of small molecules. Sci Rep. 2017;7:42717.

33. Gfeller D, Grosdidier A, Wirth M, Daina A, Michielin O, Zoete V. SwissTargetPrediction: a web server for target prediction of bioactive small molecules. Nucleic Acids Res. 2014;42(W1):W32-8.

34. Paul D, Thomas MJC, Kejariwal A, Huaiyu mi, Karlak B, Daverman R, Diemer K, Muruganujan A, Narechania A. PANTHER: a library of protein families and subfamilies indexed by function. Genome Res. 2003;13:2129-41. 
35. Szklarczyk D, Morris JH, Cook H, Kuhn M, Wyder S, Simonovic M, Santos A, Doncheva NT, Roth A, Bork P, Jensen LJ. The STRING database in 2017: quality-controlled protein-protein association networks, made broadly accessible. Nucleic acids research. 2016;gkw937.

36. Shannon P, Markiel A, Ozier O, Baliga NS, Wang JT, Ramage D, Amin N, Schwikowski B, Ideker T. Cytoscape: a software environment for integrated models of biomolecular interaction networks. Genome Res. 2003;13(11):2498-504

37. Sanberg PR. Haloperidol-induced catalepsy is mediated by postsynaptic dopamine receptors. Nat. 1980;284(5755):472-3.

38. Klemm WR. Evidence for a cholinergic role in haloperidol-induced catalepsy. Psychopharmacol. 1985;85(2):139-42.

39. Elliott PJ, Close SP, Walsh DM, Hayes AG, Marriott AS. Neuroleptic-induced catalepsy as a model of Parkinson's disease. I. Effect of dopaminergic agents. J Neural Transm Park Dis Dement Sect. 1990;2(2):79-89.

40. Polydoro M, Schroder N, Lima MN, Caldana F, Laranja DC, Bromberg E, Roesler R, Quevedo J, Moreira JC, Dal-Pizzol F. Haloperidol- and clozapineinduced oxidative stress in the rat brain. Pharmacol Biochem Behav. 2004; 78(4):751-6

41. Zucca FA, Basso E, Cupaioli FA, Ferrari E, Sulzer D, Casella L, Zecca L. Neuromelanin of the human substantia nigra: an update. Neurotox Res. 2014;25(1):13-23.

42. Spencer JP, Jenner P, Daniel SE, Lees AJ, Marsden DC, Halliwell B. Conjugates of catecholamines with cysteine and GSH in Parkinson's disease: possible mechanisms of formation involving reactive oxygen species. J Neurochem. 1998;71(5):2112-22.

43. Block ML, Zecca L, Hong JS. Microglia-mediated neurotoxicity: uncovering the molecular mechanisms. Nat Rev Neurosci. 2007;8(1):57-69.

44. Bostantjopoulou S, Kyriazis G, Katsarou Z, Kiosseoglou G, Kazis A, Mentenopoulos G. Superoxide dismutase activity in early and advanced Parkinson's disease. Funct Neurol. 1997;12(2):63-8.

45. Kim GH, Kim JE, Rhie SJ, Yoon S. The role of oxidative stress in neurodegenerative diseases. Exp Neurobiol. 2015;24(4):325-40.

46. Koeberle A, Werz O. Multi-target approach for natural products in inflammation. Drug Discov Today. 2014;19(12):1871-82.

47. Liu J, Pei M, Zheng C, Li Y, Wang Y, Lu A, Yang L. A systems-pharmacology analysis of herbal medicines used in health improvement treatment: predicting potential new drugs and targets. Evid Based Complement Alternat Med. 2013;2013:17.

48. Jeong H, Mason SP, Barabási AL, Oltvai ZN. Lethality and centrality in protein networks. Nat. 2001;411:41.

49. Azuaje FJ, Zhang L, Devaux Y, Wagner DR. Drug-target network in myocardial infarction reveals multiple side effects of unrelated drugs. Sci Rep. 2011;1:52.

50. Koschützki D, Schreiber F. Centrality Analysis Methods for Biological Networks and Their Application to Gene Regulatory Networks. Gene Regul Syst Biol. 2008;2:GRSB-S702.

51. Pommier Y, SyN H, Gao R, Das BB, Murai J, Marchand C. Tyrosyl-DNAphosphodiesterases TDP1 and TDP2. DNA Repair. 2014;19:114-29.

52. Katyal S, El Khamisy SF, Russell HR, Li Y, Ju L, Caldecott KW, PJ MK. TDP1 facilitates chromosomal single-strand break repair in neurons and is neuroprotective in vivo. EMBO J. 2007;26(22):4720-31.

53. Zhang CC, Xing A, Tan MS, Tan L, Yu JT. The role of MAPT in neurodegenerative diseases: genetics, mechanisms and therapy. Mol Neurobiol. 2016;53(7):4893-904.

54. Das G, Misra AK, Das SK, Ray K, Ray J. Microtubule-associated protein tau (MAPT) influences the risk of Parkinson's disease among Indians. Neurosci Lett. 2009;460(1):16-20.

55. Setó-Salvia N, Clarimón J, Pagonabarraga J, et al. Dementia risk in parkinson disease: disentangling the role of mapt haplotypes. Arch Neurol. 2011;68(3): 359-64.

56. Edwards YJK, Beecham GW, Scott WK, Khuri S, Bademci G, Tekin D, Martin ER, Jiang Z, Mash DC, Mullen J F, et al. Identifying consensus disease pathways in Parkinson's disease using an integrative systems biology approach. PLoS One. 2011;6(2):e16917.

57. Kong Y, Liang X, Liu L, Zhang D, Wan C, Gan Z, Yuan L. High throughput sequencing identifies MicroRNAs mediating alpha-Synuclein toxicity by targeting Neuroactive-ligand receptor interaction pathway in early stage of Drosophila Parkinson's disease model. PLoS One. 2015;10(9):e0137432.

58. Chen CPLH, Alder JT, Bray L, Kingsbury AE, Francis PT, Foster OJF. PostSynaptic 5-HT1A and 5-HT2A Receptors Are Increased in Parkinson's Disease Neocortex. Annals NY Acad Sci. 1998;861(1):288-9.
59. Politis $M$, Loane C. Serotonergic dysfunction in Parkinson's disease and its relevance to disability. TheScientificWorldJournal. 2011;11:1726-34.

60. Pagano G, Niccolini F, Politis M. The serotonergic system in Parkinson's patients with dyskinesia: evidence from imaging studies. J Neural transm Vienna. 2018;125(8):1217-23.

61. Threlfell S, Cragg SJ. Dopamine signaling in dorsal versus ventral striatum: the dynamic role of cholinergic interneurons. Front Syst Neurosci. 2011;5:11.

62. Perez-Lloret S, Barrantes FJ: Deficits in cholinergic neurotransmission and their clinical correlates in Parkinson's disease. Npj Parkinson\&\#39;S Disease 2016, 2:16001.

63. Bohush A, Niewiadomska G, Filipek A. Role of mitogen activated protein kinase signaling in Parkinson's disease. Int J Mol Sci. 2018;19(10):2973.

\section{Publisher's Note}

Springer Nature remains neutral with regard to jurisdictional claims in published maps and institutional affiliations.
Ready to submit your research? Choose BMC and benefit from:

- fast, convenient online submission

- thorough peer review by experienced researchers in your field

- rapid publication on acceptance

- support for research data, including large and complex data types

- gold Open Access which fosters wider collaboration and increased citations

- maximum visibility for your research: over $100 \mathrm{M}$ website views per year

At BMC, research is always in progress.

Learn more biomedcentral.com/submissions 